\title{
PERAN KEPUASAN KERJA DALAM MEMEDIASI PENGARUH STRES KERJA DAN MOTIVASI KERJA TERHADAP TURNOVER INTENTION
}

\author{
Dewa Made Bayu Adi Putra ${ }^{1}$ \\ Ni Wayan Mujiati² \\ ${ }^{1,2}$ Fakultas Ekonomi dan Bisnis Universitas Udayana, Bali, Indonesia \\ E-mail: dbayuadiputra@yahoo.com
}

\begin{abstract}
ABSTRAK
Penelitian ini bertujuan untuk mengetahui pengaruh turnover intention pada stres kerja dan motivasi kerja, serta peran kepuasan kerja dalam memediasi pengaruh turnover intention pada stres kerja dan motivasi kerja pada karyawan Nirmala Plaza Supermarket Jimbaran. Sampel berjumlah 34 orang karyawan dengan metode sampling jenuh. Kuesioner digunakan sebagai teknik pengumpulan data dengan pendekatan survei dan selanjutnya data dianalisis dengan SEM-PLS. Hasil memperlihatkan terdapat pengaruh positif dan signifikan stres kerja terhadap turnover intention, sedangkan pengaruh negatif dan signifikan ditunjukkan pada hubungan motivasi kerja dan kepuasan kerja terhadap turnover intention. Selain itu, hasil analisis juga menunjukkan pengaruh stres kerja dan motivasi kerja terhadap turnover intention dimediasi oleh kepuasan kerja secara parsial. Manajemen Nirmala Plaza Supermarket Jimbaran perlu mengurangi stres kerja karyawan serta meningkatkan motivasi kerja begitu juga dengan kepuasan kerja karyawan untuk bisa menekan tingkat turnover intention.
\end{abstract}

Kata kunci: motivasi kerja, stres kerja, kepuasan kerja, turnover intention

\section{ABSTRACT}

This study aim was to determine the effect of turnover intention on job stress and work motivation, and the role of job satisfaction in mediating the effect of turnover intention on job stress and work motivation at Nirmala Plaza Supermarket Jimbaran employee. The sample amounted to 34 employees with the saturated sampling method. Questionnaires were used as data collection techniques with survey approaches and then data were analyzed with SEM-PLS. The results show that there is a positive and significant effect of job stress on turnover intention, while there is a negative and significant effect of work motivation and job satisfaction on turnover intention. In addition, the results of the analysis also show that the effect of job stress and work motivation on turnover intention was mediated by job satisfaction partially. The management of Nirmala Plaza Supermarket Jimbaran needs to reduce employee job stress and increase work motivation along with the job satisfaction to reduce the turnover intention.

Keywords: work motivation, job stress, job satisfaction, turnover intention 


\section{PENDAHULUAN}

Salah satu masalah yang dianggap serius di bidang Manajemen Sumber Daya Manusia adalah permasalahan turnover, dimana permasalahan ini berhubungan dengan perputaran tenaga kerja yang tinggi (Kumar, Ramendran, \& Yacob, 2012). Turnover sendiri dapat diartikan sebagai suatu kondisi dimana karyawan atau pekerja meninggalkan perusahaan tempatnya bekerja. Hal yang mengawali terjadinya permasalahan turnover adalah adanya niatan atau keinginan dari karyawan untuk meninggalkan perusahaan yang disebut turnover intention. Turnover intention diartikan sebagai suatu keinginan untuk melakukan pergerakan karyawan di luar perusahaan yang bersifat permanen (Rahman \& Nas, 2013). Tingginya tingkat turnover di perusahaan dapat dijadikan peramalan mengenai indikasi akan terjadinya turnover intention di tahun yang akan mendatang.

Permasalahan mengenai turnover intention dianggap suatu hal yang negatif dan merugikan bagi perusahaan. Tingginya keinginan keluar yang dimiliki oleh karyawan mengisyaratkan tingginya juga perputaran karyawan yang akan terjadi, yang mengakibatkan perlunya dilakukan perekrutan ulang untuk menggantikan posisi karyawan yang meninggalkan perusahaan. Perekrutan ulang karyawan tentunya akan berakibat pada munculnya biaya perekrutan yang tidak sedikit nominalnya. Biaya ini menyangkut biaya periklanan pembukaan lowongan, biaya saat dilakukan seleksi, biaya masa orientasi karyawan, serta biaya lainnya yang mungkin timbul akibat dari perekrutan kembali tersebut. Tingginya turnover yang terdapat pada perusahaan, maka biaya yang dikeluarkan untuk melakukan 
perekrutan ulang karyawan akan menjadi semakin besar, yang menyebabkan kerugian bagi perusahaan.

Turnover intention dapat terjadi karena pengaruh beberapa variabel diantaranya stres kerja, motivasi kerja, dan kepuasan kerja (Manurung, 2012; Saputra et al., 2014; Wahyuni, Zaika, \& Anwar, 2014). Apabila karyawan merasakan stres kerja yang tinggi, maka keinginan karyawan untuk meninggalkan perusahaan juga akan meningkat (Fong \& Mahfar, 2013). Sedangkan, rendahnya motivasi kerja karyawan menyebabkan keinginan karyawan untuk meninggalkan perusahaan menjadi meningkat (Qureshi, 2013). Begitu halnya dengan rendahnya kepuasan kerja yang dirasakan karyawan, mengakibatkan turnover intention yang lebih tinggi (Hanafiah, 2014).

Permasalahan turnover intention juga terjadi di Nirmala Plaza Supermarket Jimbaran, dimana data turnovernya ditunjukkan pada Tabel 1.

Tabel 1.

Persentase Turnover Nirmala Plaza Supermarket Jimbaran

\begin{tabular}{cccccc}
\hline Tahun & $\begin{array}{c}\text { Karyawan } \\
\text { pada Awal } \\
\text { Tahun } \\
\text { (orang) }\end{array}$ & $\begin{array}{c}\text { Karyawan } \\
\text { Keluar } \\
\text { (orang) }\end{array}$ & $\begin{array}{c}\text { Karyawan } \\
\text { Masuk } \\
\text { (orang) }\end{array}$ & $\begin{array}{c}\text { Karyawan } \\
\text { pada Akhir } \\
\text { Tahun } \\
\text { (orang) }\end{array}$ & $\begin{array}{c}\text { Turnover } \\
\text { Karyawan (\%) }\end{array}$ \\
\hline & $(1)$ & $(2)$ & $(3)$ & $(4)$ & $\frac{(2)}{(1)+(4) / 2} x 100 \%$ \\
2013 & 43 & 8 & 8 & 43 & 19 \\
2014 & 43 & 13 & 13 & 43 & 30 \\
2015 & 43 & 12 & 12 & 43 & 28 \\
2016 & 43 & 17 & 17 & 43 & 40 \\
2017 & 43 & 17 & 9 & 34 & 44 \\
\hline
\end{tabular}

Sumber: HRD Nirmala Plaza Supermarket Jimbaran, 2018

Tabel 1. menunjukkan bahwa persentase turnover karyawan Nirmala Plaza Supermarket Jimbaran dari tahun 2013-2017 cenderung tinggi, bahkan dapat dikatakan mengalami peningkatan setiap tahunnya. Angka-angka tersebut telah 
melebihi 10 persen, dimana hal ini mengindikasikan bahwa terdapat permasalahan perputaran karyawan di supermarket tersebut. Apabila persentase turnover di suatu perusahaan melebihi 10 persen, dapat diartikan bahwa turnover intention atau keinginan karyawan untuk keluar dari perusahaan yang bersangkutan dapat dikatakan tinggi (Fahrizal \& Utama, 2017).

Wawancara mendalam selanjutnya dilakukan dengan lima orang karyawan Nirmala Plaza Supermarket Jimbaran yang telah keluar dari perusahaan. Wawancara ini dilaksanakan untuk menggali lebih banyak informasi mengenai halhal apa yang mempengaruhi mantan karyawan sehingga memilih untuk keluar dari Nirmala Plaza Supermarket Jimbaran. Ketidakpuasan akibat keterlambatan penerimaan gaji menjadi alasan utama dari keluarnya kelima karyawan dari perusahaan. Alasan-alasan lainnya adalah akibat beban kerja yang berlebih yang dikarenakan adanya penciutan karyawan serta kurangnya motivasi karyawan untuk bekerja yang disebabkan oleh jarangnya atasan mengapresiasi pekerjaan yang dilakukan karyawan. Oleh karena itu dipilihlah ketiga variabel yaitu motivasi kerja, kepuasan kerja, serta stres kerja sebagai variabel-variabel yang mempengaruhi turnover intention pada karyawan Nirmala Plaza Supermarket Jimbaran.

Berangkat dari latar belakang seperti yang telah dijelaskan sebelumnya, maka dapat dirumusan beberapa masalah dalam penelitian ini yaitu 1) Bagaimana pengaruh stres kerja terhadap turnover intention? ; 2) Bagaimana pengaruh motivasi kerja terhadap turnover intention? ; 3) Bagaimana pengaruh stres kerja terhadap kepuasan kerja? ; 4) Bagaimana pengaruh motivasi kerja terhadap kepuasan kerja ; 5) Bagaimana pengaruh kepuasan kerja terhadap turnover 
intention? ; 6) Bagaimana peran kepuasan kerja dalam memediasi pengaruh stres kerja terhadap turnover intention? ; 7) Bagaimana peran kepuasan kerja dalam memediasi pengaruh motivasi kerja terhadap turnover intention?

Tujuan dari dilakukannya penelitian antara lain 1) Untuk menjelaskan pengaruh stres kerja terhadap turnover intention ; 2) Untuk menjelaskan pengaruh motivasi kerja terhadap turnover intention ; 3) Untuk menjelaskan pengaruh stres kerja terhadap kepuasan kerja ; 4) Untuk menjelaskan pengaruh motivasi kerja terhadap kepuasan kerja ; 5) Untuk menjelaskan pengaruh kepuasan kerja terhadap turnover intention ; 6) Untuk menjelaskan peran kepuasan kerja dalam memediasi pengaruh stres kerja terhadap turnover intention ; 7) Untuk menjelaskan peran kepuasan kerja dalam memediasi pengaruh motivasi kerja terhadap turnover intention.

Terdapat dua manfaat dalam penelitian yang dilakukan, yaitu pertama manfaat teoritis dimana hasil penelitian ini diharapkanberikan kontribusi terhadap pengembangan ilmu pengetahuan serta dijadikan sumber referensi untuk penelitian lebih lanjut. Kedua manfaat praktis, dimana diharapkan penelitian ini dapat dijadikan sebagai dasar dalam pengambilan keputusan ketika mengadapi permasalahan mengenai turnover intention.

Turnover intention atau keinginan untuk keluar dari perusahaan adalah suatu keinginan atau niatan dari karyawan agar bisa melakukan pergerakan meninggalkan perusahaan tempatnya bekerja dan harus segera digantikan (Rahman \& Nas, 2013). Tingginya niatan karyawan atau pegawai untuk keluar dari tempatnya bekerja yang berakhir pada actual turnover, yang membuat perusahaan mengeluarkan biaya lebih dalam perekrutan karyawan baru untuk mengisi posisi yang ditinggalkan. Terdapat tiga indikator 
pengukuran turnover intention, yaitu thinking of quitting, intention to search for alternatives, and intention to quit (Model, Michaels, \& Spector, 1982).

Kepuasan kerja karyawan ialah suatu kondisi dimana pekerja atau karyawan merasa puas terhadap pekerjaan yang dilakukannya sehingga hal ini akan menimbulkan efek positif bagi pekerjaannya (Mathis dan Jackson, 2011:68). Robin dan Judge (2008:99) mengungkapkan bahwa pekerja atau karyawan yang memiliki tingkat kepuasan kerja yang tinggi akan memberikan perasaan positif pada pekerjaan yang dikerjakannya. Terdapat lima indikator yang digunakan dalam mengukur kepuasan kerja, diantaranya kepuasan pada gaji yang diterima, kepuasan pada promosi yang dirasakan, kepuasan pada pekerjaan itu sendiri, serta kepuasan pada atasan (Alshitri, 2013).

Stres kerja diartikan sebagai sebuah keadaan yang membuat seseorang merasa tertekan dimana tekanan ini berada di luar batas kemampuannya, yang mana jika berlanjut terjadi tanpa adanya solusi dan tidak segera ditanggulangi, akan berdampak terhadap kesehatan orang yang menderita stres tersebut (Fahmi, 2016: 256). Karyawan yang mengalami stres, akan mengalami beberapa gejala seperti sulit berkonsetrasi, turunnya nafsu makan, tidak bersemangat, serta mengalami masalah dalam berkomunikasi dengan orang lain. Stres kerja dapat diukur menggunakan delapan indikator (Dewi \& Wibawa, 2016), yaitu 1) merasa takut ketika ada perubahan sistem yang baru di perusahaan, 2) merasa tidak senang ketika di perusahaan ada konflik antar kelompok, 3) merasa tidak senang ketika kinerja tidak sesuai dengan pekerjaan di dalam perusahaan yang tidak memadai, 4) merasa bingung ketika memiliki dua peran pekerjaan yang berbeda dalam bekerja, 5) 
merasa jenuh apabila kualitas supervisi jelek, 6) merasa emosi apabila mendapat beban kerja yang berlebihan, 7) merasa tergesa-gesa ketika ada desakan waktu untuk menyelesaikan tugas kantor, dan 8) merasa menyerah apabila frustasi karena pekerjaan yang dikerjakan tidak sesuai dengan harapan.

Motivasi kerja merupakan dorongan yang diberikan kepada seseorang dan dalam hal ini adalah karyawan, untuk membuat karyawan tersebut mampu menyelesaikan sesuatu sesuai dengan tujuan perusahaan. Berdasarkan teori McClelland (Mada \& Mujiati, 2014), menjelaskan terdapat tiga dimensi dalam pengukuran motivasi kerja yaitu 1) motivasi berprestasi, 2) motivasi berafiliasi, dan 3) motivasi berkuasa. Dalam tiga dimensi tersebut, terdapat total enam belas indikator yang digunakan untuk mengukur motivasi kerja.

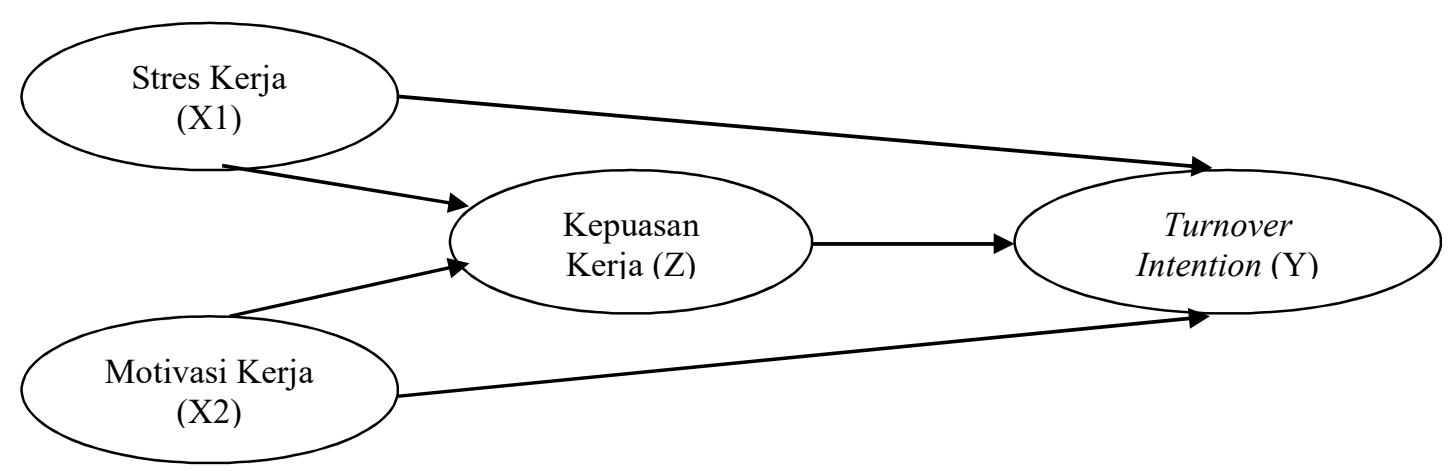

Gambar 1. Kerangka Konseptual

Sumber: Klassen dan Chiu (2011), Choi et al. (2013), Sajjad et al. (2013), Bonenberger et al. (2014), Tziner et al. (2015), Dewi dan Artha Wibawa (2016), Ahmed et al. (2010), Saleem et al. (2010), Yin-Fah et al. (2010), Wateknya dan Indartono (2016), Yuhui (2011), dan Syahgani. (2017)

Penelitian mengungkapkan bahwa pengaruh stres kerja terhadap turnover intention memiliki hubungan yang positif dan signifikan (Fong \& Mahfar, 2013). Penelitian sejenis lainnya juga menjelaskan bahwa keinginan karyawan untuk meninggalkan profesinya dipengaruhi oleh stres kerja secara signifikan dan positif 
(Klassen \& Chiu, 2011). Hasil dari penelitian serupa mengungkapkan bahwa stres kerja memiliki pengaruh signifikan dan positif pada turnover intention (Nasution, 2017). Hal serupa pun diungkapkan dalam penelitian yang dilaksanakan di Korea Selatan, yang mengungkapkan bahwa secara positif stres kerja berpengaruh terhadap turnover intention (Choi, Moon, Nae, \& Ko, 2013). Berdasarkan pemaparan tersebut, hipotesis dapat dirumuskan seperti berikut.

$\mathrm{H}_{1}$ : stres kerja berpengaruh positif dan signifikan terhadap turnover intention

Motivasi kerja secara signifikan dan negatif memiliki pengaruh terhadap turnover intention. Pengaruh negatif memiliki arti ketika motivasi kerja yang dimiliki karyawan meningkat, maka niatan karyawan untuk keluar dari tempatnya bekerja akan semakin rendah, begitupun sebaliknya. Hal ini didukung dengan hasil dari penelitian yang telah dilakukan pada sektor Telekomunikasi di Pakistan yang mengungkapkan bahwa motivasi kerja secara signifikan dan negatif berpengaruh terhadap keinginan karyawan untuk meninggalkan tempat bekerjanya (Sajjad, Ghazanfar, \& Ramzan, 2013). Motivasi kerja beserta dimensinya memiliki pengaruh yang signifikan dan negatif terhadap keinginan karyawan untuk keluar dari tempatnya bekerja (Qureshi, 2013). Pada penelitian berikutnya terungkap bahwa ada hubungan signifikan dan negatif antara motivasi kerja dengan keinginan karyawan untuk meninggalkan tempatnya bekerja di Ghana (Bonenberger, Aikins, Akweongo, \& Wyss, 2014). Berdasarkan pemaparan tersebut, hipotesis dapat dirumuskan seperti berikut.

$\mathrm{H}_{2}$ : motivasi kerja berpengaruh negatif dan signifikan terhadap turnover intention 
Tingginya tingkat stres kerja yang dirasakan karyawan dapat menurunkan kemampuan karyawan tersebut untuk menghadapi kondisi lingkungannya, yang juga akan berpengaruh terhadap menurunnya kepuasan kerja (Putradiarta \& Rahardja, 2016). Penelitian yang telah dilakukan pada dokter rumah sakit di Israel mengungkapkan hasil bahwa pengaruh dari stres kerja terhadap kepuasan kerja karyawan memiliki hubungan yang signifikan dan negatif (Tziner, Rabenu, Radomski, \& Belkin, 2015). Hal serupa juga ditemukan dalam research atau penelitian serupa, dimana stres kerja secara signifikan dan negatif mempengaruhi kepuasan kerja (Dewi \& Wibawa, 2016)d. Hasil penelitian serupa juga menemukan bahwa stres kerja berpengaruh secara signifikan dan negatif terdahap kepuasan kerja (Tunjungansari, 2011). Berdasarkan pemaparan tersebut, hipotesis penelitian dirumuskan seperti berikut.

$\mathrm{H}_{3}$ : stres kerja berpengaruh negatif dan signifikan terhadap kepuasan kerja

Motivasi kerja karyawan secara signifikan dan positif berpengaruh kepada kepuasan kerja yang dirasakan karyawan. Motivasi kerja yang tinggi akan mampu membuat kepuasan kerja karyawan dalam perusahaan menjadi meningkat. Penelitian yang dilaksanakan oleh pada tahun 2010 di Punjab, Pakistan mengungkapkan bahwa motivasi kerja yang dimiliki oleh karyawan dan faktorfaktornya memiliki pengaruh yang signifikan dan positif terhadap kepuasan kerja (Ahmed \& Ali, 2010). Hasil penelitian serupa juga menunjukkan hubungan antara motivasi kerja pada kepuasan kerja memiliki pengaruh yang signifikan dan positif (Kurnia, Sunuharyo, \& Utami, 2013). Hal serupa juga dikemukakan oleh pada penelitian yang dilakukan di Pakistan pada tahun 2010, yang mengungkapkan 
bahwa terdapat hubungan signifikan dan positif antara motivasi kerja terhadap kepuasan kerja yang dirasakan karyawan pada perusahaan pelayanan telekomunikasi di Pakistan (Saleem, Mahmood, \& Mahmood, 2010). Berdasarkan pemaparan tersebut, hipotesis dapat dirumuskan seperti berikut.

$\mathrm{H}_{4}$ : motivasi kerja berpengaruh positif dan signifikan terhadap kepuasan kerja.

Kepuasan kerja yang dirasakan karyawan memiliki pengaruh siginifikan dan negatif terhadap keinginan karyawan untuk keluar dari tempat kerjanya. Dengan meningkatnya kepuasan kerja karyawan akan berdampak pada meningkatnya komitmen karyawan yang akan menurunkan turnover intention. Hasil research yang dilaksanakan pada karyawan private sector tahun 2010, menunjukkan bahwa rendahnya kepuasan kerja yang dirasakan karyawan akan meningkatkan keinginan karyawan untuk keluar dari tempatnya bekerja (Chan Yin-Fah, Foon, Chee-Leong, \& Osman, 2010). Kepuasan kerja secara langsung memiliki pengaruh signifikan dan negatif terhadap keinginan karyawan untuk keluar dari tempat kerjanya (Tziner et al., 2015). Hasil penelitian serupa juga mengungkapkan bahwa kepuasan kerja memiliki pengaruh signifikan dan negatid terhadap turnover intention (Wateknya \& Indartono, 2015). Berdasarkan pemaparan tersebut, hipotesis dari penelitian dapat dirumuskan seperti berikut.

$\mathrm{H}_{5}$ : kepuasan kerja berpengaruh negatif dan signifikan terhadap turnover intention

Karyawan dengan tingkat stres kerja yang dapat dikatakan tinggi dalam suatu perusahaan, cenderung memiliki kepuasan kerja yang rendah. Ketika terjadi penurunan pada kepuasan kerja, maka keinginan karyawan untuk keluar atau 
meninggalkan organisasi atau perusahaan tempatnya bekerja akan meningkat. Penelitian yang dilaksanakan tahun 2011 di China mendukung penjelasan di atas dimana Yuhui mengungkapkan bahwa kepuasan kerja memediasi secara sebagian pengaruh stres kerja pada niatan karyawan untuk keluar dari tempat kerjanya (Yuhui, 2011). Penelitian serupa mengungkapkan bahwa pengaruh dari stres kerja terhadap niatan karyawan untuk meninggalkan tempatnya bekerja dimediasi oleh kepuasan kerja yang dirasakan (Tziner et al., 2015). Berdasarkan pemaparan tersebut, hipotesis dapat dirumuskan seperti berikut.

$\mathrm{H}_{6}$ : kepuasan kerja memediasi pengaruh stres kerja terhadap turnover intention

Motivasi kerja sangat berefek pada kepuasan kerja yang dirasakan karyawan. Tingginya motivasi kerja yang dimiliki seorang karyawan akan membuat kepuasan kerja yang dirasakan karyawan tersebut juga akan meningkat. Meningkatnya kepuasan kerja ini akan menurunkan keinginan karyawan untuk meninggalkan perusahaan atau organisasi tempatnya berada sekarang. Hal serupa juga diungkapkan dalam research yang dilaksanakan pada karyawan PT Avila Prima Intra Makmur Banyuwangi pada tahun 2014, mengungkapkan bahwa tingginya motivasi kerja yang dimiliki karyawan akan menciptakan kepuasan kerja yang berakibat pada menurunnya keinginan karyawan untuk meninggalkan perusahaan tempatnya bekerja (Saputra et al., 2014). Hal serupa juga menunjukkan jika motivasi kerja karyawan meningkat hal ini akan menyebabkan kepuasan kerjanya juga akan meningkat sehingga keinginan karyawan untuk meninggalkan 
perusahaan juga akan menurun(Syahgani, 2017). Berdasarkan penjelasan tersebut, hipotesis dapat dirumuskan seperti berikut.

$\mathrm{H}_{7}$ : kepuasan kerja memediasi pengaruh motivasi kerja terhadap turnover intention

\section{METODE PENELITIAN}

Desain dari penelitian ini adalah penelitian asosiatif kausalitas yang bertujuan untuk mengetahui pengaruh antara dua variabel atau lebih. Penelitian dilakukan pada Nirmala Plaza Supermarket Jimbaran. Obyek penelitian yang digunakan pada penelitian ini adalah turnover intention (Y1), kepuasan kerja (Z1), stres kerja (X1) dan motivasi kerja (X2). Sampel dalam penelitian ini berjumlah 34 orang yang seluruhnya merupakan karyawan Nirmala Plaza Supermarket Jimbaran dan sampel diambil dengan menggunkan metode sampel jenuh.

Metode pengumpulan data yang digunakan adalah metode kuesioner dengan pendekatan survei. Kuesioner disebarkan kepada karyawan Nirmala Plaza Supermarket Jimbaran yang selanjutnya kuesioner harus diisi oleh responden penelitian. Pengukuran jawaban dari responden diukur dengan menggunakan skala Likert. Teknik analisis data pada penelitian ini menggunakan analisis statistik deskriptif serta analisis statistik inferensial dengan SEM berbasis varian atau SEM-PLS.

\section{HASIL DAN PEMBAHASAN}

Karakteristik dari responden dalam penelitian ini dengan sampel sebanyak 34 responden, ditunjukkan pada Tabel 2. Tabel 2. mengenai karakteristik responden, memberikan informasi bahwa ditinjau dari segi jenis kemalin responden, sebagian 
besar adalah perempuan yaitu 19 orang (55,9 persen), sedangkan sisanya sebesar 15 orang (44,1 persen) adalah laki-laki.

Tabel 2.

Karakteristik Responden Penelitian

\begin{tabular}{cccc}
\hline Karakteristik & Kategori & Frekuensi & persentase (\%) \\
\hline \multirow{3}{*}{ Jenis Kelamin } & Laki-laki & 15 & 44.1 \\
& Perempuan & 19 & 55.9 \\
& Total & 34 & 100 \\
& 19-24 Tahun & 9 & 26.5 \\
& 25-30 Tahun & 9 & 26.5 \\
& 31-36 Tahun & 9 & 26.5 \\
Umur & 37-42 Tahun & 5 & 14.7 \\
& $\geq 43$ Tahun & 2 & 5.9 \\
& Total & 34 & 100 \\
& SMA/K & 22 & 64.7 \\
& D1 & 3 & 8.8 \\
Pendidikan Terakhir & D2 & 1 & 2.9 \\
& D3 & 5 & 14.7 \\
& S1 & 3 & 8.8 \\
& Total & 34 & 100 \\
& $\leq 1$ Tahun & 9 & 26.5 \\
Masa Kerja & 1-3 Tahun & 16 & 47.1 \\
& 3 Tahun & 9 & 26.5 \\
& Total & 34 & 100 \\
\hline
\end{tabular}

Sumber: Data Primer (diolah), 2018

Berdasarkan kelompok umur, menunjukkan bahwa 9 orang (26,5 persen) memiliki umur pada kisaran 19-24 tahun, 9 orang (26,5 persen) memiliki umur pada kisaran 25-30 tahun, 9 orang (26,5 persen) memiliki umur kisaran 31-36 tahun, 5 orang (14,7 persen) berada pada kisaran 37-42 tahun, dan 2 orang (5,9 persen) berada pada kisaran umur 43-48 tahun. Ditinjau dari segi pendidikan terakhir, 22 orang (64,7 persen) merupakan lulusan SMA/K, 3 orang (8,8 persen) merupakan lulusan D1, 1 orang (2,9 persen) merupakan lulusan D2, 5 orang $(14,7$ persen) merupakan lulusan D3, dan 3 orang (8,8 persen) merupakan lulusan S1. Sedangkan apabila ditinjau dari masa kerja, 9 orang (26.5 persen) bekerja kurang dari 1 tahun, 
16 orang (47,1 persen) bekerja antara 1-3 tahun, dan 9 orang lainnya (26,5 persen) sudah bekerja lebih dari 3 tahun.

Uji validitas serta uji reliabilitas dilakukan untuk mengetahui validitas serta mengetahui kehandalan jawaban yang diberikan oleh responden. Hasil dari kedua uji, yaitu uji validitas dan reliabilitas ditunjukkan pada Tabel 3 dan Tabel 4.

Tabel 3.

Hasil Uji Validitas Instrumen Penelitian

\begin{tabular}{|c|c|c|c|c|}
\hline No & Variabel Laten & Indikator & Kriteria & Keterangan \\
\hline 1 & Tunrover Intention & $\mathrm{Y} 1.1, \mathrm{Y} 1.2, \mathrm{Y} 1.3$ & & Valid \\
\hline 2 & Kepuasan Kerja & $\mathrm{Z} 1.1, \mathrm{Z} 1.2, \mathrm{Z} 1.3, \mathrm{Z1.4}, \mathrm{Z} 1.5$ & & Valid \\
\hline 3 & Stres Kerja & $\begin{array}{c}\mathrm{X} 1.1, \mathrm{X} 1.2, \mathrm{X} 1.3, \mathrm{X} 1.4, \mathrm{X} 1.5 \\
\mathrm{X} 1.6, \mathrm{X} 1.7, \mathrm{X} 1.8\end{array}$ & $\begin{array}{c}\text { Nilai } \\
\text { koefisien }\end{array}$ & Valid \\
\hline 4 & Motivasi Kerja & $\begin{array}{c}\mathrm{X} 2.1, \mathrm{X} 2.2, \mathrm{X} 2.3, \mathrm{X} 2.4, \mathrm{X} 2.5 \\
\mathrm{X} 2.6, \mathrm{X} 2.7, \mathrm{X} 2.8, \mathrm{X} 2.9, \mathrm{X} 2.10 \\
\mathrm{X} 2.11, \mathrm{X} 2.12, \mathrm{X} 2.13, \mathrm{X} 2.14 \\
\mathrm{X} 2.15, \mathrm{X} 2.16\end{array}$ & korelasi $>0,3$ & Valid \\
\hline
\end{tabular}

Sumber: Data Primer (diolah), 2018

Tabel 3. memperlihatkan bahwa semua pernyataan di kuesioner memiliki nilai di atas 0,3 untuk koefisien korelasinya. Hal ini berarti kuesioner dikatakan layak dan valid untuk dapat dipakai sebagai instrumen penelitian.

Tabel 4.

Hasil Uji Reliabilitas Instrumen Penelitian

\begin{tabular}{|c|c|c|c|c|c|}
\hline \multirow{2}{*}{ No. } & \multirow{2}{*}{ Variabel Laten } & \multirow{2}{*}{ Item } & \multicolumn{2}{|c|}{ Reliabilitas } & \multirow[b]{2}{*}{ Keterangan } \\
\hline & & & Alpha Cronbach & Standar & \\
\hline 1 & Turnover Intention & $\mathrm{Y}$ & 0,888 & 0,6 & Reliabel \\
\hline 2 & Kepuasan Kerja & $\mathrm{Z}$ & 0,950 & 0,6 & Reliabel \\
\hline 3 & Stres Kerja & $\mathrm{X} 1$ & 0,942 & 0,6 & Reliabel \\
\hline 4 & Motivasi Kerja & $\mathrm{X} 2$ & 0,974 & 0,6 & Reliabel \\
\hline
\end{tabular}

Sumber: Data Primer (diolah), 2018 
Tabel 4. menujukkan nilai yang lebih besar dari 0,6 untuk alpha Cronbach dari keempat variabel yang digunakan dalam penelitian. Oleh karena itu instrumen penelitian sudah dapat dikatakan reliabel.

Ada dua tahapan dalam analisis data menggunakan SEM-PLS, yaitu 1) evaluasi model pengukuran (outer model) dan 2) evaluasi model struktural (inner model).

Outer model atau juga disebut dengan evaluasi model pengukuran dilakukan dengan tujuan untuk melakukan pengukuran validitas dan reliabilitas dari indikator tiap variabel laten yang digunakan dalam penelitian. Evaluasi model ini dilakukan dalam tiga tahapan, yaitu 1) Convergent validity, 2) Discriminant validity, dan 3) Composite reliability.

Convergent validity atau yang dikenal juga dengan validitas konvergensi adalah suatu proses yang dilakukan untuk mengetahui validitas dari indikator dengan dasar bahwa indikator dari variabel laten harusnya memiliki korelasi yang tinggi dengan variabel latennya. Untuk bisa tau korelasi dari indikator variabel laten, dapat diketahui dengan melihat nilai outer loading dari masing-masing indikator variabel laten yang digunakan dalam model penelitian. Indikator dapat dikatakan valid ketika nilai loading-nya yang dimiliki berada di atas nilai 0,60. Indikator-indikator yang memiliki nilai outer loading di atas 0,6 dan dikatakan valid dapat digunakan untuk mengukur nilai dari variabel yang akan diukur dengan baik. 
Tabel 5.

Validitas Indikator-Indikator Turnover Intention (Y1), Kepuasan Kerja (Z1), Stres Kerja (X1) dan Motivasi Kerja (X2) berdasarkan Outer Loadings

\begin{tabular}{|c|c|c|}
\hline Indikator & Outer Loadings & Keterangan \\
\hline Y1.1 & 0,931 & Valid \\
\hline Y1.2 & 0,867 & Valid \\
\hline Y1.3 & 0,900 & Valid \\
\hline Z1.1 & 0,962 & Valid \\
\hline $\mathrm{Z} 1.2$ & 0,835 & Valid \\
\hline Z1.3 & 0,903 & Valid \\
\hline $\mathrm{Z} 1.4$ & 0,870 & Valid \\
\hline $\mathrm{Z} 1.5$ & 0,933 & Valid \\
\hline $\mathrm{X} 1.1$ & 0,919 & Valid \\
\hline $\mathrm{X} 1.2$ & 0,857 & Valid \\
\hline $\mathrm{X} 1.3$ & 0,813 & Valid \\
\hline $\mathrm{X} 1.4$ & 0,847 & Valid \\
\hline $\mathrm{X} 1.5$ & 0,849 & Valid \\
\hline $\mathrm{X} 1.6$ & 0,792 & Valid \\
\hline $\mathrm{X} 1.7$ & 0,858 & Valid \\
\hline $\mathrm{X} 1.8$ & 0,882 & Valid \\
\hline X2.1 & 0,921 & Valid \\
\hline $\mathrm{X} 2.2$ & 0,842 & Valid \\
\hline $\mathrm{X} 2.3$ & 0,881 & Valid \\
\hline $\mathrm{X} 2.4$ & 0,838 & Valid \\
\hline $\mathrm{X} 2.5$ & 0,844 & Valid \\
\hline $\mathrm{X} 2.6$ & 0,880 & Valid \\
\hline X2.7 & 0,871 & Valid \\
\hline $\mathrm{X} 2.8$ & 0,849 & Valid \\
\hline $\mathrm{X} 2.9$ & 0,819 & Valid \\
\hline $\mathrm{X} 2.10$ & 0,845 & Valid \\
\hline $\mathrm{X} 2.11$ & 0,848 & Valid \\
\hline $\mathrm{X} 2.12$ & 0,716 & Valid \\
\hline $\mathrm{X} 2.13$ & 0,871 & Valid \\
\hline $\mathrm{X} 2.14$ & 0,871 & Valid \\
\hline $\mathrm{X} 2.15$ & 0,820 & Valid \\
\hline $\mathrm{X} 2.16$ & 0,810 & Valid \\
\hline
\end{tabular}

Sumber: Data Primer (diolah), 2018

Tabel 5. memperlihatkan bahwa nilai outer loading dari indikator-indikator pada seluruh variabel laten telah berada di atas nilai 0,6 , sehingga sesuai dengan penjelasan sebelumnya indikator-indikator yang membentuk seluruh variabel laten dapat dikatakan valid. 
Untuk mengetahui validitas variabel laten melalui Discriminant validity dapat dilakukan dengan melihat nilai dari Average Variance Extracted (AVE) dari setiap variabel. Indikator dari masing-masing variabel laten dapat dikatakan valid apabila nilai AVE dari setiap variabel berada di atas nilai 0,5 .

Tabel 6.

Validitas Indikator-Indikator Turnover Intention (Y1), Kepuasan Kerja (Z1), Stres Kerja (X1), dan Motivasi Kerja (X2) berdasarkan koefisien Average Variance Extracted (AVE)

\begin{tabular}{ccc}
\hline Variabel Laten & Koefisien AVE & Keterangan \\
\hline Turnover Intention & 0,810 & Valid \\
Kepuasan Kerja & 0,813 & Valid \\
Stres Kerja & 0,727 & Valid \\
Motivasi Kerja & 0,717 & Valid \\
\hline
\end{tabular}
Sumber: Data Primer (diolah), 2018

Tabel 6 memperlihatkan nilai AVE dari indikator yang membentuk variabel laten telah berada di atas nilai 0,5 . Oleh karena itu, sesuai dengan penjelasan discriminant validity sebelumnya, indikator-indikator yang membentuk variabel laten dapat dikatakan valid.

Suatu variabel dikatakan reliabel jika koefisien Cronbach Alpha dan Composite reliability nya berada di atas 0,60 .

Tabel 7.

Uji Reliabilitas Variabel Turnover Intention (Y1), Kepuasan Kerja (Z1), Stres Kerja (X1), dan Motivasi Kerja (X2)

\begin{tabular}{cccc}
\hline Variabel & Koefisien Cronbach Alpha & Composite Reliability & Keterangan \\
\hline Turnover Intention & 0,882 & 0,927 & reliabel \\
Kepuasan Kerja & 0,942 & 0,956 & reliabel \\
Stres Kerja & 0,946 & 0,955 & reliabel \\
Motivasi Kerja & 0,973 & 0,976 & reliabel \\
\hline
\end{tabular}

Sumber: Data Primer (diolah), 2018 
Tabel 7. menunjukkan bahwa koefisien Cronbach Alpha dan nilai dari Composite Reliability seluruh variabel laten telah berada di atas nilai 0,60 . Hal ini mengisyaratkan bahwa seluruh variabel laten dalam tabel dapat dikatakan reliabel.

Inner model atau kerap disebut dengan evaluasi model struktural dilakukan dengan tujuan untuk mencari tau seberapa besar variabel laten bebas memiliki korelasi terhadap variabel laten terikatnya. Untuk evaluasi model ini dilakukan dengan dua tahapan, yaitu 1) $R$-Square $\left(R^{2}\right)$ dan 2) $Q$-Square Predictive Relevance $\left(Q^{2}\right)$.

Evaluasi $R$-Square $\left(R^{2}\right)$ bertujuan untuk mengetahui seberapa besar variabel laten bebas mempengaruhi variabel laten terikatnya. Semakin dekat nilai $\mathrm{R}^{2}$ dengan 1 menunjukkan perngaruh yang semakin besar antara variabel bebas dengan variabel terikatnya.

\section{Tabel 8.}

Pengaruh Variabel Turnover Intention, Kepuasan Kerja, Stres Kerja, dan Motivasi Kerja

\begin{tabular}{lccc}
\hline \multicolumn{1}{c}{ Variabel Laten Bebas } & Variabel Laten Terikat & $\mathrm{R}^{2}$ & Keterangan \\
\hline Stres Kerja (X1) dan Motivasi Kerja (X2) & Kepuasan Kerja (Z1) & 0,749 & Baik \\
Stres Kerja (X1), Motivasi Kerja (X2), dan & Turnover Intention (Y1) & \multirow{2}{*}{0,875} & \multirow{2}{*}{ Baik } \\
Kepuasan Kerja (Z1) & & &
\end{tabular}

Tabel 8. memperlihatkan bahwa stres kerja (X1) dan motivasi kerja (X2) memiliki pengaruh yang baik pada kepuasan kerja (Z1) yaitu sebesar 0,749 atau 74,9 persen. Begitu pula dengan pengaruh variabel laten stres kerja (X1), motivasi kerja (X2), dan kepuasan kerja (Z1) pada turnover intention (Y1) yang memiliki pengaruh sebesar 0,875 atau 87,5 persen yang tergolong pengaruh yang baik. 
Pengujian $Q$-Square Predictive Relevance $\left(Q^{2}\right)$ dilakukan untuk mengetahui setepat apakah variabel laten bebas dapat digunakan untuk memprediksi besar variabel laten terikatnya. Semakin dekat nilai dari $Q^{2}$ dengan 1 , maka nilai prediksinya akan menjadi semakin kuat. Sebaliknya, semakin dekat nilai $Q^{2}$ dengan 0, ini berarti nilai prediksi dari variabel laten bebas ke variabel laten terikatnya akan menjadi lemah. Perhitungan $Q^{2}$ dijabarkan seperti berikut.

$$
\begin{array}{ll}
Q^{2} & =1-\left(1-\mathrm{R}^{2}\right)\left(1-\mathrm{R}^{2}\right) \ldots \ldots \ldots \\
& =1-(1-0,749)(1-0,875) \\
& =1-(0,251)(0,125) \\
& =1-0,031375 \\
Q^{2} & =0,9686
\end{array}
$$

Perhitungan $Q^{2}$ seperti yang dilakukan di atas, dapat diketahui bahwa untuk mengetahui nilai dari $Q^{2}$ perlu dilakukan perhitungan dengan menggunakan nilai dari $\mathrm{R}^{2}$, baik dari $\mathrm{R}^{1}{ }_{1}$ maupun $\mathrm{R}^{2}{ }_{2}$ nya. Dalam penelitian ini di dapatkan nilai dari $Q^{2}$ nya adalah sebesar 0,9686 atau 96,86 persen. Nilai $Q^{2}$ sebesar 96,86 persen tergolong ke dalam kategori memiliki kekuatan prediksi yang kuat. Hasil ini mengisyaratkan bahwa seluruh variabel laten bebas yaitu stres kerja (X1), motivasi kerja (X2), dan kepuasan kerja (Z1) sudah tepat dan kuat digunakan untuk memprediksi variabel laten terikatnya, yaitu turnover intention (Y1) sebesar 96,86 persen. 


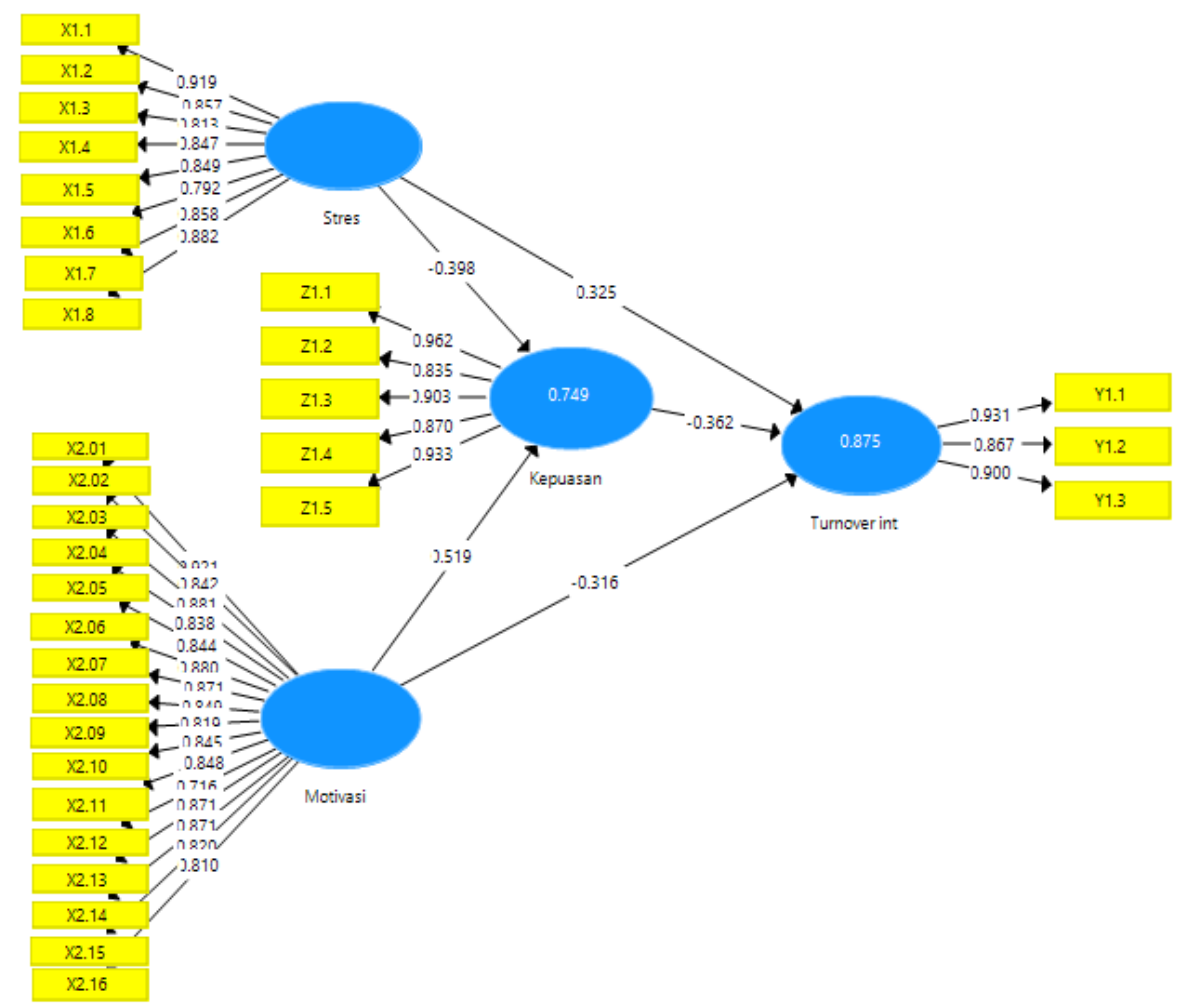

\section{Gambar 2. Diagram Jalur Variabel Turnover Intention (Y1), Kepuasan Kerja} (Z1), Stres Kerja (X1), dan Motivasi Kerja (X2)

Tabel 9.

Path Coefficient antara Variabel Turnover Intention (Y1), Kepuasan Kerja (Z1), Stres Kerja (X1), dan Motivasi Kerja (X2)

\begin{tabular}{lccc}
\hline \multicolumn{1}{c}{ Hubungan Antar Variabel } & Path Coefficient & T-Statistics & Keterangan \\
\hline Stres Kerja (X1) $\rightarrow$ Turnover Intention $(\mathrm{Y} 1)$ & 0,325 & 2,505 & Signifikan \\
Motivasi Kerja (X2) $\rightarrow$ Turnover Intention $(\mathrm{Y} 1)$ & $-0,316$ & 2,826 & Signifikan \\
Stres Kerja (X1) $\rightarrow$ Kepuasan Kerja (Z1) & $-0,398$ & 2,530 & Signifikan \\
Motivasi Kerja (X2) $\rightarrow$ Kepuasan Kerja (Z1) & 0,519 & 3,425 & Signifikan \\
Kepuasan Kerja (Z1) $\rightarrow$ Turnover Intention $(\mathrm{Y} 1)$ & $-0,362$ & 3,014 & Signifikan \\
\hline
\end{tabular}
Sumber: Data Primer (diolah), 2018

Gambar 2 dan Tabel 9. menunjukkan hasil pengolahan data untuk analisis jalur pengaruh langsung antar variabel laten. Ditunjukkan bahwa stres kerja berpengaruh signifikan dan positif terhadap turnover intention dengan nilai path coefficient atau koefisien jalur sebesar 0,325 serts nilai dari T-statistiknya sebesar 
2,505 > 1,96 (alpha 5 persen). Hal ini berarti ketika karyawan merasakan stres kerja yang tingg, hal ini akan membuat niatan karyawan untuk meninggalkan perusahaan juga akan meningkat. Selanjutnya, motivasi kerja berpengaruh secara signifikan dan negatif terhadap turnover intention dengan nilai path coefficient atau koefisien jalur sebesar -0,316 serta nilai dari T-statistiknya sebesar 2,826 > 1,96 (alpha 5 persen). Ini mengisyaratkan apabila motivasi kerja yang dimiliki karyawan rendah, hal ini akan menyebabkan niat karyawan untuk meninggalkan perusahaan anak meningkat. Stres kerja berpengaruh secara signifikan negatif terhadap kepuasan kerja dengan nilai path coefficient atau koefisien jalur sebesar -0,398 serta nilai dari T-statistiknya sebesar 2,530 > 1,96 (alpha 5 persen). Hal ini mengisyaratkan ketika karyawan merasakan stres kerja yang tinggi, hal ini akan membuat kepuasan kerja yang dihasilkan karyawan akan menjadi rendah.

Motivasi kerja berpengaruh secara signifikan positif pada kepuasan kerja dengan nilai path coefficient atau koefisien jalur sebesar 0,519 serta nilai dari Tstatistiknya sebesar 3,425 >1,96 (alpha 5 persen). Hal ini berarti ketika karyawan memiliki motivasi kerja yang tinggi, ini akan sejalan dengan peningkatan kepuasan kerja yang juga akan menjadi meningkat. Terakhir, kepuasan kerja berpengaruh secara negatif dan signifikan terhadap turnover intention dengan nilai koefisien jalur sebesar -0,362 dan nilai T-statistik sebesar 3,014 > 1,96 (alpha 5 persen). Ini memiliki arti apabila karyawan menunjukkan kepuasan kerja yang rendah, maka niat karyawan untuk meninggalkan tempatnya bekerja akan menjadi meningkat. 
Tabel 10.

Total Indirect Effect Mediasi Kepuasan Kerja pada Pengaruh Stres Kerja dan Motivasi Kerja Terhadap Turnover Intention

\begin{tabular}{lccc}
\hline \multicolumn{1}{c}{ Hubungan Antar Variabel } & $\begin{array}{c}\text { Path } \\
\text { Coefficient }\end{array}$ & T-Statistics & Keterangan \\
\hline $\begin{array}{l}\text { Stres Kerja (X1) } \rightarrow \text { Kepuasan Kerja (Z1) } \rightarrow \text { Turnover } \\
\text { Intention (Y1) }\end{array}$ & 0,144 & 2,103 & signifikan \\
$\begin{array}{l}\text { Motivasi Kerja (X2) } \rightarrow \text { Kepuasan Kerja (Z1) } \rightarrow \\
\text { Turnover Intention }(\mathrm{Y} 1)\end{array}$ & $-0,188$ & 2,001 & signifikan \\
\hline Sumber: Data Primer (diolah), 2018 & & &
\end{tabular}

Tabel 10. menunjukkan hasil pengolahan data pengaruh tidak langsung variabel laten bebas terhadap variabel laten terikan yang dimediasi variabel kepuasan kerja. Hasilnya menunjukkan bahwa variabel laten kepuasan kerja memediasi pengaruh stres kerja terhadap turnover intention secara signifikan dengan nilai T-statistik sebesar 2,103 > 1,96 (alpha 5 persen). Hal ini berarti karyawan dengan tingkat stres kerja yang tinggi akan memiliki kepuasan kerja yang rendah dan hal ini akan meningkatkan niat karyawan untuk meninggalkan perusahaan.

Selain itu, hasil juga menunjukkan variabel laten kepuasan kerja memediasi pengaruh motivasi kerja terhadap turnover intention secara signifikan dengan nilai T-statistik sebesar 2,001 >1,96 (alpha 5 persen). Ini berarti apabila motivasi kerja yang dimiliki karyawan rendah, maka kepuasan kerja yang dirasakan juga akan rendah sehingga keinginan karyawan untuk meninggalkan perusahaan akan menjadi meningkat. Begitupun sebaliknya, apabila motivasi kerja yang dimiliki oleh karyawan tinggi hal ini akan mengakibatkan karyawan akan merasakan kepuasan kerja yang tinggi pula yang akan membuat keinginan karyawan untuk keluar dari tempat kerjanya atau turnover intention nya akan menjadi rendah. 


\section{Tabel 11.}

Perhitungan Nilai Variance Accounted for Mediation (VAF) Peran Kepuasan Kerja Dalam Memediasi Pengaruh Stres Kerja Terhadap Turnover Intention

\begin{tabular}{llc}
\hline & \multicolumn{1}{c}{ Hubungan Variabel } & Koefisien \\
\hline Pengaruh Langsung & $\begin{array}{l}\text { Stres kerja } \rightarrow \text { Turnover Intention } \\
\text { Pengaruh Tidak Langsung }\end{array}$ & $\begin{array}{l}\text { Stres Kerja } \rightarrow \text { Kepuasan Kerja } \rightarrow \text { Turnover Intention } \\
(-0,398) \times(-0,362)\end{array}$ \\
Pengaruh Total & $\begin{array}{l}\text { Stres kerja } \rightarrow \text { Turnover Intention } \\
(0,325)+(0,144)\end{array}$ & 0,144 \\
VAF & $\begin{array}{l}\text { Pengaruh Tidak Langsung dibagi Pengaruh Total } \\
(0,144) \text { dibagi }(0,469)\end{array}$ & 0,469 \\
\hline Sumber: Data Primer (diolah), 2018 & 0,307 \\
\hline
\end{tabular}

Tabel 11. memperlihatkan mengenai perhitungan nilai Variance Accounted for Mediation (VAF) yang digunakan untuk mengetahui pengaruh dari variabel pemediasi, apakah mediasi sebagian/parsial atau mediasi penuh. Apabila persentase $\mathrm{VAF}>80$ persen maka menunjukkan peran mediasi penuh, sedangkan apabila berada di kisaran 20 persen hingga 80 persen maka memiliki peran pemediasi parsial (Hermawan \& Hasibuan, 2018). Nilai VAF untuk hipotesis keenam menunjukkan angka sebesar 0,307 atau 30,7 persen yang berarti variabel laten kepuasan kerja memediasi pengaruh stres kerja pada turnover intention secara parsial.

Tabel 12.

Perhitungan Nilai Variance Accounted for Mediation (VAF) Peran Kepuasan Kerja Dalam Memediasi Pengaruh Motivasi Kerja Terhadap Turnover Intention

\begin{tabular}{llc}
\hline & \multicolumn{1}{c}{ Hubungan Variabel } & Koefisien \\
\hline Pengaruh Langsung & Motivasi Kerja $\rightarrow$ Turnover Intention & $-0,316$ \\
Pengaruh Tidak Langsung & $\begin{array}{l}\text { Motivasi Kerja } \rightarrow \text { Kepuasan Kerja } \rightarrow \text { Turnover Intention } \\
(0,519) \times(-0,362)\end{array}$ & $-0,188$ \\
Pengaruh Total & Motivasi Kerja $\rightarrow$ Turnover Intention \\
& $(-0,316)+(-0,188)$ & $-0,504$ \\
VAF & Pengaruh Tidak Langsung dibagi Pengaruh Total & 0,373 \\
& $(-0,188)$ dibagi $(-0,504)$ & \\
\hline Sumber: Data Primer (diolah), 2018
\end{tabular}


Tabel 12. memperlihatkan nilai VAF sebesar 0,373 atau 37,3 persen. Ini menandakan bahwa variabel laten kepuasan kerja memediasi pengaruh motivasi kerja pada turnover intention secara parsial.

\section{SIMPULAN DAN SARAN}

Simpulan yang dapat ditarik dari penelitian yang dilakukan ini yaitu pertama, stres kerja berpengaruh signifikan dan positif terhadap turnover intention pada karyawan Nirmala Plaza Supermarket Jimbaran, yang berarti ketika karyawan merasakan stres kerja yang tinggi maka niatan karyawan untuk keluar dari tempatnya bekerja juga akan meningkat. Kedua, motivasi kerja memiliki pengaruh secara signifikan dan negatif pada keinginan untuk keluar dari karyawan Nirmala Plaza Supermarket Jimbaran. Ini berarti apabila karyawan memiliki motivasi kerja yang rendah maka niatan karyawan untuk keluar dari perusahaan juga akan mengalami peningkatan. Ketiga, stres kerja memiliki pengaruh secara signifikan dan negatif pada kepuasan kerja karyawan Nirmala Plaza Supermarket Jimbaran. Ini menunjukkan apabila karyawan merasakan stres kerja yang tinggi, kepuasan kerja yang dirasakan karyawannya akan menjadi rendah. Keempat, motivasi kerja memberikan pengaruh secara signifikan dan positif pada kepuasan kerja untuk karyawan Nirmala Plaza Supermarket Jimbaran. Hal ini menunjukkan apabila motivasi kerja yang dimiliki karyawan tinggi maka akan terjadi peningkatan juga pada kepuasan kerja yang dirasakan karyawan.

Kelima, kepuasan kerja memberikan pengaruh secara signifikan dan negatif pada niatan karyawan untuk keluar dari Nirmala Plaza Supermarket Jimbaran. Ini menunjukkan apabila karyawan atau pekerja yang merasakan kepuasan kerja yang 
rendah cenderung memiliki niatan yang lebih besar untuk meninggalkan tempatnya bekerja. Keenam, kepuasan kerja memediasi pengaruh stres kerja pada turnover intention secara signifikan pada karyawan Nirmala Plaza Supermarket Jimbaran. Karyawan yang memiliki tingkat stres kerja yang semakin tinggi, cenderung akan membuat karyawan merasakan penurunan pada kepuasan kerjanya dimana hal ini juga akan mengakibatkan pada meningkatnya niatan karyawan untuk meninggalkan tempatnya bekerja. Ketujuh, kepuasan kerja memediasi pengaruh motivasi kerja pada turnover intention secara signifikan pada karyawan Nirmala Plaza Supermarket Jimbaran. Ini berarti karyawan yang mempunyai motivasi kerja yang rendah cenderung merasakan kepuasan kerja yang lebih rendah dimana hal ini akan membuat niatan karyawan untuk keluar dari tempatnya bekerja menjadi lebih besar.

Saran yang dapat diberikan kepada manajemen Nirmala Plaza Supermarket Jimbaran yaitu pertama, manajemen perlu memperhatikan segala kebutuhan yang diperlukan karyawannya seperti kebutuhan akan gaji, kebutuhan akan motivasi dalam bekerja serta kebutuhan lainnya, sehingga keinginan karyawan untuk meninggalkan perusahaan dapat diminimalisir. Kedua, untuk menjaga kepuasan kerja karyawan manajemen perlu memperhatikan pemberian gaji ke karyawannya agar sesuai dengan apa yang dikerjakan oleh karyawan. Ketiga, manajemen perlu menjaga hubungan antar karyawan agar tidak terjadi konflik antar kelompok di perusahaan, sehingga tingkat stres kerja yang dirasakan karyawan tidak menjadi tinggi. Terakhir, untuk menjaga motivasi kerja karyawan tetap tinggi, manajemen perlu memberikan dorongan untuk maju yang lebih kuat kepada karyawan, memperhatikan keinginan karyawan untuk mengendalikan orang lain, serta 
memperhatikan keinginan karyawan yang selalu ingin memimpin di setiap kegiatan di perusahaan. Dengan memperhatikan hal-hal tersebut diharapkan dapat menekan tingkat turnover intention di Nirmala Plaza Supermarket Jimbaran.

\section{REFERENSI}

Ahmed, I., \& Ali, I. (2010). Effects of motivational factors on employees job satisfaction a case study of university of the Punjab, Pakistan. International Journal of Business and Management, 5(3), 70-80.

Alshitri, K. (2013). An Investigation of Factors Affecting Job Satisfaction among R\&amp;D Center Employees in Saudi Arabia. The Journal of Human Resources Management Research, 2013, 1-10. https://doi.org/10.5171/2013.279369

Bonenberger, M., Aikins, M., Akweongo, P., \& Wyss, M. (2014). The effects of health worker motivation and job satisfaction on turnover intention in Ghana: a cross-sectional study. Human Resources for Health, 12, 43. https://doi.org/10.1186/1478-4491-12-43

Chan Yin-Fah, B., Foon, Y. S., Chee-Leong, L., \& Osman, S. (2010). An Exploratory Study on Turnover Intention among Private Sector Employees. International Journal of Business and Management, 5(8), 57-64. https://doi.org/10.5539/ijbm.v5n8p57

Choi, B. K., Moon, H. K., Nae, E. Y., \& Ko, W. (2013). Distributive justice, job stress, and turnover intention: Cross-level effects of empowerment climate in work groups. Journal of Management and Organization, 19(3), 279-296. https://doi.org/10.1017/jmo.2013.35

Dewi, A. B., \& Wibawa, A. (2016). Pengaruh Stres Kerja pada Turnover Intention yang Dimediasi Kepuasan Kerja Agen AJB BUMIPUTERA. E-Jurnal Manajemen Unud, 5(2), 762-789.

Fahrizal, \& Utama, I. W. M. (2017). Pengaruh Persepsi Dukungan Organisasi Terhadap Komitmen Organisasional dan Turnover Intention Karyawan Hotel Kajane MUA Ubud. E-Jurnal Manajemen Unud, 6(10), 5405-5431.

Fong, Y. L., \& Mahfar, M. (2013). Relationship between occupational stress and turnover intention among employees in a furniture manufacturing company in Selangor. Jurnal Teknologi (Sciences and Engineering), 64(1), 33-39. https://doi.org/10.11113/jt.v64.1673 
Hanafiah, M. (2014). Pengaruh Kepuasan Kerja dan Ketidakamanan Kerja (Job Insecurity) dengan Intensi Pindah Kerja (Turnover) pada Karyawan PT Buma Desa Suaran Kecamatan Sambaliung Kecamatan Berau. EJournal Psikologi, 1(3), 202-312.

Hermawan, R. T., \& Hasibuan, S. (2018). Analisis pengaruh tingkat pengalaman dan coaching style terhadap kualitas kepemimpinan manajer proyek dalam upaya peningkatan produktivitas di PT. JCI. Jurnal PASTI, XI(1), 84-97.

Klassen, R. M., \& Chiu, M. M. (2011). The occupational commitment and intention to quit of practicing and pre-service teachers: Influence of self-efficacy, job stress, and teaching context. Contemporary Educational Psychology, 36(2), 114-129. https://doi.org/10.1016/j.cedpsych.2011.01.002

Kumar, R., Ramendran, C., \& Yacob, P. (2012). A Study on Turnover Intention in Fast Food Industry: Employees' Fit to the Organizational Culture and the Important of their Commitment. International Journal of Academic ..., 2(5), 9-43. Retrieved from http://www.hrmars.com/admin/pics/733.pdf

Kurnia, A. M., Sunuharyo, B. S., \& Utami, H. N. (2013). Pengaruh Motivasi Kerja Terhadap Kepuasan Kerja dan Prestasi Kerja Karyawan (Studi Pada Karyawan PT. ASKES (Persero), Cabang Boyolali), 62(19), 1-8. https://doi.org/10.7498/aps.62.197303

Mada, I. G. N. C., \& Mujiati, N. W. (2014). Kekuasaan Dalam Perspektif Gender. E-Jurnal Manajemen Unud, 3(6), 1633-1652.

Manurung, M. T. (2012). Analisis Pengaruh Stres Kerja dan Kepuasan Kerja Terhadap Turnover Intention Karyawan, 1, 1-83.

Model, M., Michaels, C. E., \& Spector, P. E. (1982). Cause of employee turnover: A test of the Mobley, Griffeth, Hand, and Meglino Model. Journal of Applied Psychology, 67(1), 53-59.

Nasution, M. I. (2017). Pengaruh Stres Kerja, Kepuasan Kerja Dan Komitmen Organisasi Terhadap Turnover Intention Medical Representative. Jurnal Ilmiah Manajemen, VII(3), 407-428.

Putradiarta, A. A., \& Rahardja, E. (2016). Analisis Pengaruh Kepuasan Kerja, Komitmen Organisasional, dan Stres Kerja Terhadap Turnover Intention. Diponegoro Journal of Management, 5(4), 1-9. Retrieved from http://ejournal-s1.undip.ac.id/index.php/dbr

Qureshi, S. (2013). The Relationship between Work Motivation, Burnout and Intention to Leave for the Top Level Managers of Garment Industry (A Case Study of Indian Garment Industry). International Journal of Human Resource Studies, 3(4), 128. https://doi.org/10.5296/ijhrs.v3i4.4609 
Rahman, W., \& Nas, Z. (2013). Employee development and turnover intention: Theory validation. European Journal of Training and Development, 37(6), 564-579. https://doi.org/10.1108/EJTD-May-2012-0015

Sajjad, A., Ghazanfar, H., \& Ramzan, M. (2013). Impact of Motivation on Employee Turnover in Telecom Sector of Pakistan. Journal of Business Studies Quarterly, 5 (1), 76-92.

Saleem, R., Mahmood, A., \& Mahmood, A. (2010). Effect of Work Motivation on Job Satisfaction in Mobile Telecommunication Service Organizations of Pakistan. International Journal of Business and Management, 5(11), 213-222.

Saputra, Y. D., Lelly, S. W., Saleh, C., Manajemen, J., Ekonomi, F., Unej, U. J., \& Kalimantan, J. (2014). Pengaruh Budaya Organisasi Dan Motivasi Terhadap Turnover Intention Melalui Kepuasan Kerja Karyawan Pada PT Avila Prima Intra Makmur Banyuwangi. Jurnal Universitas Jember, 6(5), 112-118.

Syahgani, R. (2017). Turnover Intention Karyawan Melalui Kepuasan Kerja Sebagai Variabel Intervening ( Studi Kasus pada Karyawan PT Intinusa Selareksa, Tbk). Jurnal Ilmu Administrasi Bisnis, 6(2), 213-215.

Tunjungansari, P. (2011). Pengaruh Stress Kerja terhadap Kepuasan Kerja Karyawan pada Kantor Pusat PT. Pos Indonesia (Persero) Bandung. Universitas Komputer Indonesia, 1(1), 1-14.

Tziner, A., Rabenu, E., Radomski, R., \& Belkin, A. (2015). Journal of Work and Organizational Psychology Work stress and turnover intentions among hospital physicians: The mediating role of burnout and work satisfaction. Journal of Work and Organizational Psychology, 31, 207-213. https://doi.org/10.1016/j.rpto.2015.05.001

Wahyuni, A. S., Zaika, Y., \& Anwar, R. (2014). Analisis faktor-faktor yang mempengaruhi turnover intention (keinginan berpindah) karyawan pada perusahaan jasa kontruksi. Jurnal Rekayasa Sipil, 8(2), 89-95.

Wateknya, Y., \& Indartono, S. (2015). Pengaruh komitmen organisasi dan kepuasan kerja terhadap turnover intention. Jurnal Manajemen Bisnis Indonesia, 5(5), 468-480.

Yuhui, L. (2011). Occupational stressors, turnover intention and the mediating influence of job satisfaction: Evidence from China. 2011 IEEE International Conference on Quality and Reliability, ICQR 2011, (1983), 341-344. 